\title{
Sistemas BIM no Ensino de Arquitetura: Uma Investigação do Processo de Ensino de Geometria Descritiva e Desenho Arquitetônico através de Elementos Construtivos Virtuais
}

\author{
BIM Systems in Architecture Teaching: Research on the Process of Teaching Descriptive Geometry and \\ Architectural Design through Virtual Constructive Elements
}

\author{
Mateus Moreira Pontes \\ Universidade Federal de Minas Gerais \\ mateus.pontes@gmail.com
}

\begin{abstract}
This article discusses the current conditions for learning basic knowledge of architectural drawing and descriptive geometry by incorporating geometric modeling software and modeling building components, aimed at developing a significant learning and objective skills improvement for the practice of architecture design.
\end{abstract}

Keywords: Descriptive geometry; Architectural representation; BIM.

\section{Introdução}

O objetivo do presente trabalho é trazer a questão do ensino da instrumentação para a representação do projeto de arquitetura, sob a ótica da incorporação dos processos computacionais mais atuais, em particular a modelagem tridimensional com base em geometria, através da utilização de softwares genéricos, e com base no objeto, através da utilização de softwares de Building Information Modeling (BIM.) Os dois caminhos apresentam pontos distintos de conflito ou afirmação dos processos usuais do desenho técnico, em particular de arquitetura, e alteram a demanda pelos suportes teóricos fundamentais, relativos às geometrias plana e descritiva.

\section{O ensino de geometria no contexto atual}

Uma primeira questão se coloca sobre a pertinência do ensino da geometria descritiva no contexto atual, permeado pelos softwares de modelagem tridimensional e distante dos processos gráficos bidimensionais usados no ensino tradicional da disciplina (Marconi, 2012). A pergunta que deriva desse contexto contemporâneo de ensino e desenvolvimento é como deve ser o ensino da geometria descritiva apoiado por esta tecnologia, no qual os problemas originais se mantem, afinal o trabalho com a representação do espaço tridimensional continua necessário, porém o ferramental para se trabalhar com os problemas desta disciplina é completamente novo? Alguns pesquisadores defendem a intensificação do aspecto matemático, com a inclusão de processos paramétricos de geração das formas geométricas (Vaz e Pereira, 2012). Neste sentido há uma necessidade maior da compreensão da representação do espaço por seu ferramental matemático numérico e menos do ferramental gráfico. Isso se dá em função da operação direta com as relações matemáticas demandadas pelos softwares paramétricos. Aparentemente trata- se de um distanciamento dos métodos gráficos desenvolvidos por Monge no século XVIII.

Uma questão similar pode ser evocada, relacionada porém de maneira mais direta ao ensino da representação em arquitetura, ao desenho arquitetônico. Nos processos tradicionais de ensino de desenho arquitetônico temos uma prática que se desenvolve a partir dos estudos e representações dos objetos construtivos típicos, como escadas e telhados (Montenegro, 2001) apoiados em uma formação anterior nas geometrias, pré-requisito para este aprendizado. Podemos usar softwares BIM, que da mesma maneira se apoiam na ideia dos elementos construtivos e suas regras geométricas básicas para ensinar sobre a edificação aos alunos e consequentemente também sobre a representação destes elementos? Neste sentido, em que momento é possível introduzir tais ferramentas no currículo do aluno, de maneira a permitir sua eficiência enquanto ferramenta de ensino e garantir que tal introdução não traga com ela qualquer tipo adicional de restrição criativa e de representação? (Pontes e Menezes, 2012)

Entre os dois extremos temos a modelagem geométrica pura, sem relação direta com os objetos construtivos nem com as demandas pela compreensão algébrica das relações matemáticas. Nesse caso, a reflexão sobre os elementos no espaço e a solução de problemas relativos a operações com tais elementos são questões em si, operadas tanto pelo software de maneira automática quanto pelo seu operador.

\section{Hipótese de trabalho}

O incorporação dos softwares no cotidiano daqueles que pensam e representam o espaço alterou significativamente o uso dos 
conhecimentos de geometria e desenho, primeiramente com a substituição das ferramentas de desenho como esquadro e compasso e a incorporação de softwares e desenho e modelagem geométricas. Em seguida ocorreu a incorporação da modelagem associada ao objeto construtivo, que cuida de maneira automatizada de questões geométricas e de representação, afastando ainda mais o usuário, arquiteto ou estudante, dos conhecimentos básicos e teóricos das geometrias e do desenho. Se antes já havia um certo distanciamento entre teoria e prática, neste contexto os conhecimentos fundamentais podem parecer ainda menos úteis, pois não são praticados nem encontram lugar objetivo no dia a dia daqueles que usam os softwares.

A partir das observações espontâneas que o ensino de um software BIM levantava nos alunos uma série de questões relativas à construção, uma dificuldade adicional no uso do software, foi formulada a hipótese de que o aprendizado de todos estes aspectos, geometria plana, geometria descritiva, desenho arquitetônico e técnicas construtivas, poderiam estar fundidos em um único momento. É claro que se trata de uma abrangência muito grande de conteúdos, se avaliarmos tudo o que é considerado necessário e cobrado em disciplinas isoladas de cada uma dessas matérias. Porém podemos também pensar que é possível desenvolver tantos conhecimentos de maneira simultânea, com menor profundidade, que vai se obtendo em semestres consecutivos de trabalho. No lugar de uma sequência de pré-requisitos, um processo único, simultâneo. Tal abordagem encontra força no conceito de aprendizado significativo de Ausubel (Moreira, 1982), que defende que a contextualização do objeto e o reforço de significado dado pela sua aplicação imediata ou por sua relação com outros objetos torna seu aprendizado mais pleno.

\section{Proposta para aplicação}

As questões apresentadas acima foram tratadas preliminarmente com uma mesma hipótese para aplicação nos currículos do ensino de arquitetura de maneira específica, mas que pode também ser expandida para qualquer outra situação que envolva representação de forma e espaço. A ideia é a utilização dos próprios softwares que alteram as relações de aprendizado e a forma de aplicação das estratégias tradicionais de representação do espaço, sem delas se descolarem, para o ensino dos elementos básicos de representação, tanto na geometria descritiva quando no desenho arquitetônico. Para levar adiante tal hipótese, foi formulado uma proposta pedagógica dentro de uma disciplina do curso de arquitetura noturno da UFMG, atualmente em curso, ainda sem resultados.

No referido curso, todos os conteúdos de caráter instrumental (desenho projetivo, desenho arquitetônico, modelagem tridimensional, tratamento gráfico e diagramação) encontram-se em uma única disciplina, a Oficina de Fundamentação e
Instrumentação, com carga horária total de 240 horas cumpridas em um único semestre.

A proposta em curso é para alunos de primeiro período do curso de arquitetura matriculados na disciplina. É um pressuposto do projeto pedagógico do curso a incorporação total do computador enquanto ferramenta de projeto, sem a utilização de instrumentos como esquadro e régua paralela, sendo o desenho praticado apenas a mão livre, tanto como desenhos de observação quanto desenhos de desenvolvimento e prospecção.

Os alunos são introduzidos às questões básicas da geometria descritiva através da utilização do software de modelagem geométrica Sketchup, tanto nas aulas teóricas para a apresentação das noções espaciais e dos problemas típicos quanto para a sua utilização como ferramenta para a representação dos sistemas de projeção cilíndrica e cônica. São trabalhados então problemas típicos como a caracterização e interseção de planos no espaço e estes problemas são resolvidos tanto através do ferramental bidimensional do sistema projetivo quanto através dos facilitadores de operações do próprio software. Os resultados são comparados e derivam-se novas práticas de retroalimentação, gerando representações bidimensionais a partir da solução dada pelo modelo tridimensional e vice-versa, reconstruindo o resultado tridimensional a partir dos elementos bidimensionais encontrados. Por fim, tudo é sistematicamente repetido em desenhos a mão livre em escala, de caráter prospectivo.

Em um segundo momento, os alunos são introduzidos em um software de modelagem de elementos construtivos, neste caso o Autodesk Revit. A opção por descrevê-lo como feito acima e não como BIM é em função daquilo que se pretende realçar na prática, não o caráter informacional que o BIM traz consigo, mas sim a característica de modelagem de objeto que lhe é peculiar, na qual as questões construtivas são aquelas que definem o conteúdo do modelo. Neste momento o aluno é orientado a repetir o problema trabalhado de maneira puramente geométrica, como no caso da interseção dos planos no espaço, mas já em uma aplicação construtiva, no caso a representação de um telhado e a solução da interseção das diversas águas.

Ao observar o mesmo problema por três pontos de vista diferentes, os alunos tiveram a oportunidade de exercitar o olhar e o aprendizado de maneira significativa, tornando a compreensão de cada um dos aspectos mais plena e permitindo o cruzamento maior de informações e a compreensão da necessidade dos aspectos mais abstratos para a concretização de operações muito objetivas. O mesmo procedimento foi aplicado para elementos construtivos como taludes, rampas, escadas e paredes e pisos, ortogonais e não ortogonais. A partir de cada um dos objetos construtivos que se tornaram problema de desenvolvimento e representação, foram trabalhadas questões geométricas que passaram por interseção de planos, geração de formas de 
complexidade média, formas de representação a partir dos vários sistemas de projeção e também questões construtivas como materiais usados, soluções estruturais típicas, partes que compõe cada um dos elementos, regras e práticas construtivas, etc. Por fim, o desenho a mão livre com e sem escala foram estimulados como ferramentas de apoio no entendimento daquilo que estava sendo trabalhado, através de croquis de partes ou do todo presente nos exercícios.

Existem algumas dificuldades já enfrentadas no processo praticado no semestre em curso e a dificuldade em lidar com os softwares é uma delas. Em algum momento fica difícil de distinguir uma dificuldade na compreensão dos aspectos teóricos trabalhados ou uma limitação na operação da ferramenta. Os croquis servem um pouco para clarear esta questão e apoiar os estudantes. No entanto eles já conseguem trabalhar de maneira significativa, produzindo as soluções tanto para as questões geométricas puras quanto para as questões construtivas associadas. Não há, porém, a prática sistemática do desenho enquanto ferramenta de investigação e prospecção, sendo que tais ações acabam concentradas no próprio processo de modelagem. As limitações muitas vezes encontram-se nas ferramentas, assim como as possibilidades, e podemos supor uma interferência considerável no processo de formação deste estudante, que pode ser limitador por um lado, mas também pode ser ampliado por outro, com o desenvolvimento próprio de novos métodos adaptados às ferramentas digitais.

Acreditamos que trata-se de uma inversão do processo tradicional, no qual primeiro temos contato com situações extremamente abstratas para representarmos o espaço, através de projeção de linhas e planos e suas interseções, para um processo mais concreto, ainda que virtual, no qual partimos já do espaço tridimensional representado e o transformamos, usando ainda a mesma lógica estabelecida por Gaspar Monge, em uma representação bidimensional. Tal inversão contribui claramente para a incorporação do conceito de aprendizado significativo, em uma abordagem bastante pragmática e independente do background do estudante, procurando criar as oportunidades de apoio cognitivo dentro do próprio processo de ensino, através da repetição por caminhos distintos. Ainda é cedo para dizer se a direção tomada na disciplina significa uma superação no processo de ensino das ferramentas instrumentais de representação do espaço, mas certamente apontará potenciais e limitações destas escolhas, para serem ou definitivamente incorporadas junto ao curso ou para reforçarem a necessidade da permanência de uma prática mais ligada diretamente ao desenho propriamente dito, que traz consigo claramente um grande potencial de desenvolvimento cognitivo. É fundamental o acompanhamento dos estudantes durante o seu caminho no curso, inclusive com a incorporação de um apoio pedagógico durante a prática projetual, a fim de se permitir a avaliação completa do processo proposto inclusive nas disciplinas de projeto, pois nelas se reforçam processos e técnicas desenvolvidas nas disciplinas instrumentais. Terminamos com a proposta de seguir com este acompanhamento sistemático, através de entrevistas e questionários a serem trabalhados com os estudantes e também com os docentes responsáveis pelas disciplinas de projeto do curso.

\section{Referências}

Mathews, J., Berrett, D., \& Brillman, D. (2005, May 16). Other winning equations. Newsweek, 145(20), 58-59.

Marconi, R. (2012) Geometria Descritiva e Ambiente CAD Reposicionamento e Contextualização de Seu Escopo e Ensino. In: XVI Congresso da Sociedade Iberoamericana de Gráfica Digital, Fortaleza: Expressão Gráfica e Editora, 2012. P. 259-262

Vaz, Carlos Eduardo Verzola. Pereira, Natália. A modelagem paramétrica e o ensino de geometria descritiva: as superfícies de Felix Candela. In: XVI Congresso da Sociedade Iberoamericana de Gráfica Digital, Fortaleza: Expressão Gráfica e Editora, 2012. P. 216-218

Pontes, Mateus Moreira; Menezes, Alexandre Monteiro. BIM e o ensino: possibilidades na instrumentação e no projeto. In: XVI Congresso da Sociedade Iberoamericana de Gráfica Digital, Fortaleza: Expressão Gráfica e Editora, 2012. P. 226-228

Moreira, Marco A, Masini, Elcie F. Salzano: Aprendizagem significativa: a teoria de David Ausubel - São Paulo: Moraes, 1982.112p 